\title{
Güneş Enerji Panellerindeki Optimum Eğim Açısının Verime Etkisinin İncelenmesi
}

\section{Investigation of the Effect of Optimum Tilt Angle on Yield in Solar Energy Panels}

\begin{abstract}
Ali Riza Dal ${ }^{1 *}$
Geliş / Received: 11/02/2021

Revize / Revised: 13/03/2021

Kabul / Accepted: 17/03/2021

ÖZ

Fosil yakıtlardan elde edilen enerji çevre ve insan sağlığını olumsuz yönde etkilemektedir. Dünyada enerji tüketimine bağlı olarak gelişen olumsuz etkiyi azaltmak için Uluslararası Yenilenebilir Enerji Ajansı tarafından yeni tedbirler uygulanmaya başlanmıştır. Bu tedbirlerin başında güneş enerjisine dayalı elektrik üretimi gelmektedir. Bu çalışma, Kayseri'de yapılacak olan güneş enerjisi yatırımlarında kullanılan güneş panellerinin güneş ışınımından daha iyi faydalanmalarını sağlamak için yapılmıştır. Yapılan çalışmada, panellerin aylık, mevsimlik ve altı aylık performansları ile optimum eğim açısının tespit edilmesi amaçlanmıştır. Çalışma kapsamında, güneş 1şınımı tespitinde Fotovoltaik Coğrafi Bilgi Sistemi (PVGIS), eğim açılarının tespitinde ise PVGIS ve Hottel \& Woertz (HW) metotları kullanılmıştır. Hesaplamalar sonucunda; PVGIS ve HW metotları arasındaki açı farkının yaz aylarında $10,6^{\circ}$ 'ye kadar çıktığı, yılın son dört ayında ise birbirleriyle aynı değerleri aldığı görülmüş̧ür. Kayseri'de güneş panellerinin her ay farklı sabit bir optimum eğim açısı ile konumlandırılması durumunda 1852,3 $\mathrm{kWh} / \mathrm{m}^{2}$ maksimum güneş 1şınımı elde edilmiştir. Yıllık 29,5'’lik eğim açısıyla konumlandırılan güneş paneline göre; aylık, mevsimsel ve altı aylık olarak değiştirilen panel eğim açılarındaki verimin sırasıyla yılda $\% 4,11, \% 3,25$ ve $\% 2,99$ arttı̆ı tespit edilmiştir. Aylık optimum eğim açısı ile konumlandırmanın büyük avantaj sağladığı anlaşılmıştır. Mevsimsel ve altı aylık optimum eğim açıları karşılaştırıldığında ise verim farkı yüzde 0,26 olduğu saptanmıştır. Bu farkın az olması, güneş panellerinin yılda iki kez (altı aylık) eğim açısını değiştirerek konumlandırmasının uygun olacağını göstermiştir.
\end{abstract}

Anahtar Kelimeler- Optimum Eğim Açısı, Güneş Paneli, Güneş Işınımı, PVGIS

\begin{abstract}
Energy obtained from fossil fuels negatively affects the environment and human health. In order to reduce the negative impact of energy consumption in the world, new precautions have been implemented by the International Renewable Energy Agency. Electricity generation based on solar energy comes first among these precautions. This study was carried out to ensure that the solar panels used in solar energy investments to be made in Kayseri benefit from solar radiation better. In the study, it was aimed to determine the optimum tilt angle with monthly, seasonal and semi-annual performances of the panels. Within the scope of the study, Photovoltaic Geographical Information System (PVGIS) was used to detect solar radiation, and PVGIS and Hottel \& Woertz (HW) methods were used to determine the slope angles. As a result of the calculations; It was observed that the angle difference between the PVGIS and HW methods increased up to $10.6^{\circ}$ in the summer months, and took the same values in the last four months of the year. In Kayseri, if solar panels are positioned with a different fixed optimum tilt angle each month, a maximum solar irradiance of $1852.3 \mathrm{kWh} / \mathrm{m}^{2}$ has been achieved. According to the solar panel
\end{abstract}

1*Sorumlu yazar iletişim: ardal1969@gmail.com (https://orcid.org/0000-0002-3646-2288)

Ulaştırma ve Altyapı Bakanlığı, Çankaya, Ankara, Türkiye 
positioned with an annual inclination angle of $29.5^{\circ}$; It has been determined that the yield in panel slope angles, which are changed monthly, seasonally and semi-annually, increased by $4.11 \%, 3.25 \%$ and $2.99 \%$ per year, respectively. It has been understood that positioning with the monthly optimum angle of inclination provides a great advantage. When the seasonal and six-month optimum slope angles were compared, it was found that the yield difference was 0.26 percent. The fact that this difference is low has shown that it would be appropriate to position the solar panels by changing the angle of inclination twice a year (six months).

\section{Keywords- Optimum Tilt Angle, Solar Panel, Solar Radiation, PVGIS}

\section{GİRIS}

Toplumların kalkınması ve gelişen teknoloji enerjideki tüketimi artırmaktadır. Enerji tüketimindeki bu artış beraberinde iklim değişikliğine neden olmaktadır. Yenilenebilir enerji kaynakları hem iklim değişikliği hem de ülkemizin enerjide dışa bağımlılığını azaltıcı bir etkiye sahiptir. Diğer taraftan, fosil yakıtlardan elde edilen enerji çevre ve insan sağlığını olumsuz yönde etkilemektedir. Dünyada enerji tüketimine bağlı olarak gelişen olumsuz etkiyi azaltmak için Uluslararası Yenilenebilir Enerji Ajansı tarafindan yeni tedbirler uygulanmaya başlanmıştır. Bu tedbirlerin alınması, iklim değişikliğini en aza indirmenin yollarından biri olan güneş enerji sistemlerine yatırım yapılmasını zorunlu hale getirmektedir.

Güneş enerjisinde kullanılan panellerde en önemli parametreden biri güneş 1şınımıdır. Güneş 1şınları yıl içerisinde Dünya üzerine farklı açılarda gelmektedir. Uygulamada güneş panelleriyle toplanan güneş 1şınımı miktarı; panelin eğim açısına, zamana, panelin konulduğu yöne ve bölgeye bağlı olarak değişir. Güneş panellerinden maksimum performans elde etmek için panelin yatayla yaptığı açı önemli bir parametredir. Güneş panelleri yatayla sabit bir açı yapacak şekilde konumlandırılabileceği gibi ay ve mevsimlere göre değişen bir eğim açısıyla güneye bakacak şekilde de konumlandırılabilir. Bu nedenle panellerden etkin fayda sağlanmak için eğim açısının uygun bir şekilde belirlenmesi gerekir.

Literatürde farklı bölgelerin enlemlerine bağlı olarak farklı modellerde birçok çalışma yapılmıştır. Bu modeller kullanılarak güneş panellerin eğim açılarındaki güneş 1şınımından faydalanma verimleri incelenmiştir. Güneş panellerinden elde edilen enerji miktarı; enlem ve panelin yüzey ile yaptığı eğim açısına göre değişmektedir [1]. Kaldellis ve Zafirakis yaptıkları deneysel bir çalışmada tüm yaz dönemi için Atina'da güneş panel optimum eğim açısını $15^{\circ}\left( \pm 2,5^{\circ}\right)$ olarak belirlemişlerdir [2]. Lubitz [3] yaptı̆̆ çalışmada yıl boyunca eğim açısını aylık olarak değiştirilen panellerin, sabit panellere göre yıllık ortalama $\% 5$ daha fazla güneş 1şınımı aldığını bulmuştur. Ülgen [4] İzmir için yaptığı çalışmada güney yönlü güneş panellerin optimum eğim açılarını yaz ayları için $\varphi-34^{\circ}$, kış ayları için $\varphi+19^{\circ}$ ve yıllık optimum eğim açısını ise $30,3^{\circ}$ olarak bulmuştur. Bulut ve arkadaşları [5], tarafından Kayseri için 38,43 enlem açısında yedi yıllık veriler esas alınarak yapılan trigonometrik çalışmada, yıllık toplam yatay düzleme gelen 1şınımı $1349 \mathrm{kWh} / \mathrm{m}^{2}$ olarak belirtmişlerdir. Khatib ve arkadaşları [6], Malezya'da beş bölge için yaptıkları çalışmada, panellerin aylık optimum eğim açıları ile konumlandırılmasındaki verim artışını \%6,13, mevsimlik optimum eğim açıları ile konumlanmasındaki verim artışını \%5,85 olarak bulmuşlardır. Le Roux [7], Güney Afrika'da yaptığı çalışmada, optimum eğimde sabitlenmiş kolektörlerin yataya sabitlenmiş kolektörlere göre \%10 daha fazla 1şınım aldığını bulmuştur. Yıldırım ve Aktacir [8] tarafından Şanlıurfa'da yapılan çalışmada, güneye yönlendirilen panellerin yıllık sabit optimum bir eğimde yatay $\left(0^{\circ}\right)$ durumdaki panele göre verimi $\% 11,5$ bulmuşlardır. Çağlar [9], dört şehir (İstanbul, Ankara, Erzurum, Adana) için yaptığı çalışmada, söz konusu şehirlerin her ay için optimum eğim açılarını tespit etmiştir. Koçer ve arkadaşları [10] tarafından Ankara ve ilçelerinde yapılan çalışmada, sadece güneş panellerin verimliliğini arttırmak için eğim açısını ayda bir kez veya yılda en az iki kez değiştirilmesini tavsiye etmişlerdir. Aydın [11], tarafından Kayseri için $39^{\circ}$ enlem kabul edilerek yapılan çalışmada, optimum güneş paneli eğim açısı $32^{\circ}$ olarak bulunmuştur.

Enerji ve Tabi Kaynaklar Bakanlığı tarafından hazırlanan Güneș Enerji Potansiyeli Atlası [12] Şekil 1'de görülmektedir. Şekil 1 incelendiğinde Orta Anadolu Bölgesinin güneş enerjisi potansiyeli bakımından avantajlı bölgeler arasında yer aldığg görülmektedir. Güneş enerjisi yatırımları açısından Kayseri’nin diğer illere göre daha öncelikli olduğu anlaşılmaktadır.

Kayseri'de güneş enerji potansiyelinin yüksek olmasına karşın bölgenin Türkiye'deki toplam kurulu güç kapasitesindeki payının \%0,144 olduğu, bu payın diğer bölgelere göre az ve artırılması gerektiği ifade edilmektedir [13]. Kayseri bazlı güneş panellerine ilişkin aylık, mevsimlik ve altı aylık optimum eğim açılarına ilişkin yeterli çalışma bulunmamaktadır. Bu nedenle Kayseri'de kullanılan güneş panellerinin performansını şimdikinden daha 
fazla artırmak için PVGIS metodunda yapılan simülasyonla güneş paneli eğim açısının güneş ışınımı verimine etkisi incelenmiştir. PVGIS ve HW metotları ile güneş panellerinin eğim açısının aylık (yılda on iki kez), mevsimlik (yılda dört kez) ve altı aylık (yılda iki kez) değiştirilmesi ile optimum eğim açıları karşılaştırılmıştır. Yapılan çalışma ile yatırımcı ve araştırmacılara literatür kazandırılması amaçlanmıştır.

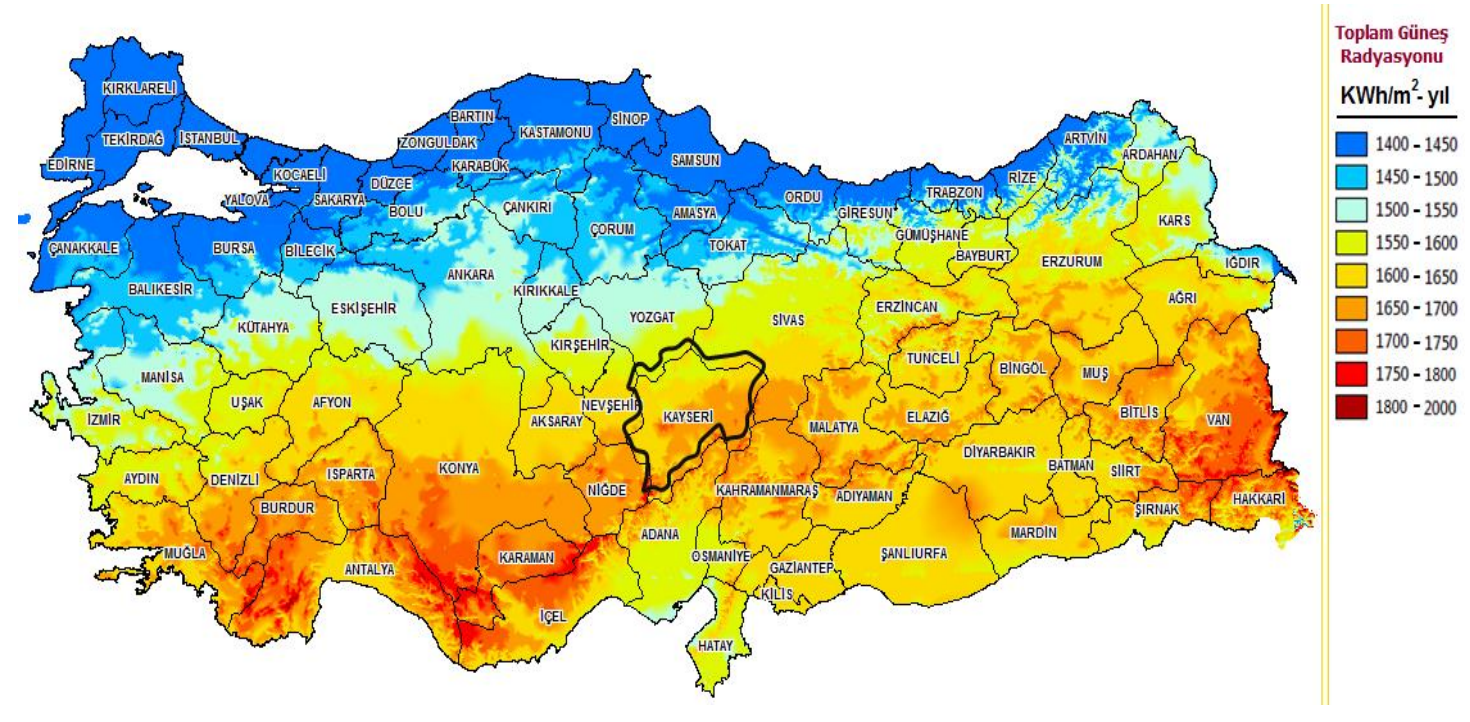

Şekil 1. Türkiye'nin güneş ışınım potansiyeli dağılımı [12]

\section{MATERYAL METOD}

Güneş 1şınımından maksimum fayda sağlamak için optimum panel eğim açısı tespitinde çeşitli tahmin metotları ve simülasyon programları araştırmacılar tarafından kullanılmaktadır. Bu sayede gerçeğe yakın analizlerin yapılması daha da kolaylaşmıştır. Bu çalışmada hesaplama metodolojisi olarak PVGIS ile HW metodu kullanılmıştır.

\section{A. PVGIS Metodu}

PVGIS metodu, Avrupa Komisyonu tarafından geliştirilen ve kullanıcılara ücretsiz olarak sunulan bir simülasyon programdır. PVGIS metodu uydu etkileşimli meteorolojik verileri kullanarak hesaplama yapmaktadır. PVGIS metodu veri tabanı ile istenilen coğrafi konuma ve panel eğim açısına bağlı olarak optimum saatlik, günlük, aylık ve yıllık güneş ışınımı değerlerini farklı opsiyonlarda simüle etmektedir [14].

PVGIS metodunda eğimli yüzeylere gelen toplam güneş 1şınımı; güneş azimut açısı, güneş yükseklik açısı ve eğim açısı değerlerine bağlı olarak aşağıda verilen eşitliklerle hesaplanmaktadır [15]:

$$
G_{T}=G_{b T}+G_{d T}+G_{r T}
$$

Eşitlik 1'de verilen $G_{T}$ eğimli yüzeye gelen toplam ışınım olup, $G_{b T}, G_{d T}$ ve $G_{r T}$ sırasıyla eğimli yüzeye gelen direkt, difüz ve yansıyan 1 şınımı $\left[\mathrm{W} / \mathrm{m}^{2}\right]$ ifade etmektedir.

$$
G_{b T}=G_{b} \frac{\cos \xi}{\cos \sigma_{z}}
$$

Eşitlik 2'de verilen $G_{b T}$; güneş konumu, yüzey eğimi ve azimut açısına göre değişkenlik göstermektedir. Burada, $G_{b}$ yatay düzleme gelen direkt güneş 1 şınımı $\left[\mathrm{W} / \mathrm{m}^{2}\right]$, $\xi$ direkt 1şınım geliş açısı $\left[{ }^{\circ}\right], \sigma_{z}$ ise zenit açısıdır $\left.{ }^{\circ}\right]$.

Eğimli yüzeye gelen yansıyan güneş 1şınımı;

$$
G_{r t}=G \frac{(1-\cos \beta)}{2}
$$


şeklinde ifade edilmektedir. Eşitlik 3'de; $G$ yatay düzleme gelen toplam $1 s ̧ ı n ı m ı ~\left[W / \mathrm{m}^{2}\right], \rho$ albedo olarak ifade edilen yüzey yansıtma oranını (birimsiz), $\beta$ ise panel yüzeyin eğim açısını $\left[{ }^{\circ}\right]$ belirtmektedir.

Difüz 1şınım, güneş ışınımının atmosferin bileşenleri tarafindan dağılmasının bir sonucu olup, gökyüzünde homojen dağılım yoktur. Burada izotropik ve anizontropik model olarak üzere iki yaklaşım söz konusudur. PVGIS metodunda uygulanan model Muneer tarafindan [16] geliştirilmiş olup, anizotropik modeller kategorisinde sınıflandırılır. Bu model; gökyüzünün açık ve bulutlu, güneşli ve gölgeli durumları arasında ayrım yaparak $G_{d T}$ 'yi tahmin etmektedir [15].

PVGIS gölgeli veya bulutlu durumlar için Eşitlik 4 ile bulutsuz gökyüzü koşulları altındaki güneşli durumlar için Eşitlik 5 formüllerini kullanmaktadır.

$$
\begin{aligned}
G_{d T}= & G_{d} \cdot\left[\left(\frac{1+\cos \beta}{2}\right)+0,25227 \cdot\left(\sin \beta-\beta \cdot \cos \beta-\pi \cdot\left(\sin \frac{\beta}{2}\right)^{2}\right)\right] \\
G_{d T}= & G_{d \cdot} \cdot\left[\left(\left(\frac{1+\cos \beta}{2}\right)+\left(\sin \beta-\beta \cdot \cos \beta-\pi \cdot\left(\sin \frac{\beta}{2}\right)^{2}\right) \cdot\left(0,00263-0,712 \cdot \frac{G_{b}}{G_{o}}-\right.\right.\right. \\
& \text { 0,6883. } \left.\left.\left.\left(\frac{G_{b}}{G_{o}}\right)^{2}\right)\right) \cdot\left(1-\frac{G_{b}}{G_{o}}\right)+\left(\frac{G_{b}}{G_{o}} \cdot \frac{\cos \xi}{\cos \sigma_{z}}\right)\right]
\end{aligned}
$$

Burada $G_{d}$ yatay düzleme gelen difüz güneş 1 şınımı $\left[\mathrm{W} / \mathrm{m}^{2}\right], G_{o}$ atmosfer dışı toplam güneş 1şınımını [W/m²] ifade etmektedir. Bu koşullar altında güneş yükseliş açısı $\alpha_{s}<0,1[\mathrm{rad}]$ olduğu durumda $G_{d T}$ aşağıdaki Eşitlik 6 ile hesaplanmaktadır.

$$
\begin{aligned}
G_{d T}= & G_{d} \cdot\left[\left(\left(\frac{1+\cos \beta}{2}\right)+\left(\sin \beta-\beta \cdot \cos \beta-\pi \cdot\left(\sin \frac{\beta}{2}\right)^{2}\right) \cdot\left(0,00263-0,712 \cdot \frac{G_{b}}{G_{o}}-\right.\right.\right. \\
& \text { 0,6883. } \left.\left.\left.\left(\frac{G_{b}}{G_{o}}\right)^{2}\right)\right) \cdot\left(1-\frac{G_{b}}{G_{o}}\right)+\left(\frac{G_{b}}{G_{o}} \cdot \frac{\sin \beta \cdot \cos \left(\gamma-\gamma_{s}\right.}{0,1-0,008 \cdot \alpha_{s}}\right)\right]
\end{aligned}
$$
etmektedir.

PVGIS metodu toplam global güneş ı̧̧ınımını panel eğimi ve $\gamma_{s}$ azimut açısına $\left[{ }^{\circ}\right]$ bağlı olarak simüle

$\mathrm{Bu}$ çalışmada, Kayseri'de enlemi $38,666^{\circ}$ ve boylamı $35,693^{\circ}$ olan bir konum seçilmiştir. PVGIS'ta kullanılan güneş paneli azimut açısı güney $\left(0^{\circ}\right)$ olarak kabul edilmiştir. Program ile aylık, mevsimlik, altı aylık ve yıllık optimum eğim açıları hesaplanmıştır.

PVGIS metodu ile optimum eğim açısının tespitinde; eğim açılı güneş paneline gelen aylık, mevsimlik ve altı aylık ortalama güneş ışınımlarının maksimum değeri dikkate alınarak bulunmuştur. Maksimum değerdeki açılar, o ayın, mevsimin ve altı ayın optimum eğim açısı olarak kabul edilmiştir. Sonuçlar Microsoft Excel programı yardımıyla hesaplanmış ve grafik haline getirilmiştir.

Örnek olarak Kayseri'de Temmuz ayında maksimum güneş ışınımını elde etmek için gereken optimum eğim açıları PVGIS metodu ile hesaplanmıştır. Hesaplanan değerlerin dağılımı Şekil 2'de verilmiştir. 


\begin{tabular}{|c|c|c|}
\hline & $\begin{array}{l}\text { BŞEÜ Fen Bilimleri Dergisi } \\
8(1), 241-250,2021\end{array}$ & $\begin{array}{r}\text { BSEU Journal of Science } \\
\text { https://doi.org/10.35193/bseufbd } 878795\end{array}$ \\
\hline & & 2458-7575 (https://dergipark.org.tr/tr/pub/bseufbd) \\
\hline
\end{tabular}

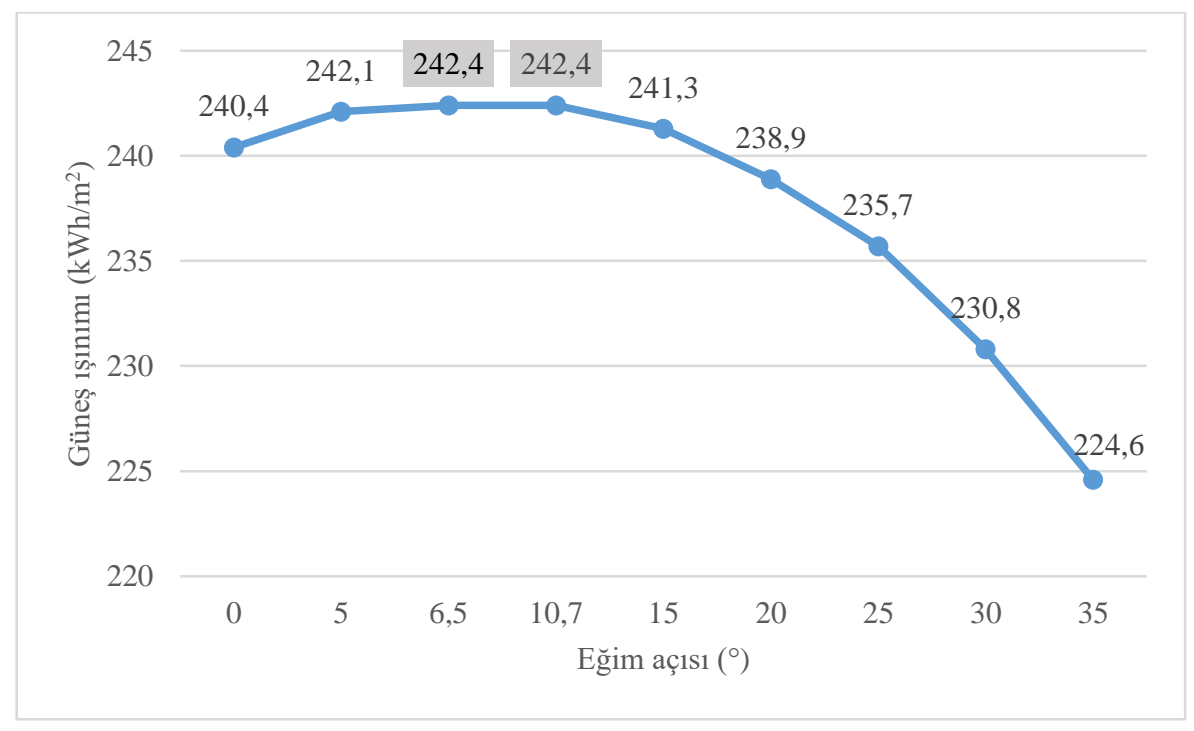

Şekil 2. Temmuz ayı için optimum eğim açısının belirlenmesi

Hesaplamalar neticesinde Temmuz ayı için güneş paneli eğim açısııın değişimi ile güneş ışınımının maksimum değere ulaştığı açı belirlenmiştir. Ş̧ekil 2'de görüldüğü üzere, Temmuz ayında panel eğim açısı $6,5^{\circ}$ $10,7^{\circ}$ arasında olması durumunda panele $242,4 \mathrm{kWh} / \mathrm{m}^{2}$ lik maksimum güneş ışınımı ulaşmaktadır. Belirlenen açı aralığının orta noktası $8,6^{\circ}$ olup bu değer; PVGIS metodunda o ay için güneş paneli aylık optimum eğim açısı, elde edilen maksimum güneş ışınımı ise PVGIS metodunda o ay için optimum güneş ışınımı olarak kabul edilmiştir. Bu işlemler her aylık, her mevsim ve her altı aylık için ayrı ayrı yapılarak belirlenmiştir.

\section{B. Hottel \& Woertz Metodu}

HW metodu güneş panellerinin eğim açısının belirlenmesinde kullanılan kolay bir metottur. Bu metottaki hesaplamalar bulutsuz, çevrede engel veya yansitıcıların olmadığı ideal şartlarda yapılmaktadır. Bu durum panel eğim açısının basit bir şekilde bulunmasını sağlamaktadır. Daha çok sistem tasarımlarında ön analiz yapılırken kullanılan bir yöntem olarak bilinmektedir [9]. Güneş paneli eğim açısı Eşitlik 7 ile bulunmaktadır.

$$
\beta=\varphi-\delta
$$

Burada, $\beta$ güneş paneli eğim açısını, $\varphi$ panelin bulunduğu konumun enlemini $\left[{ }^{\circ}\right]$ ve $\delta$ deklinasyon açısını $\left[{ }^{\circ}\right]$ ifade etmektedir $[17,18]$.

Güneş 1şınlarının dünyaya geliş doğrultusunun ekvator düzlemi ile yaptığı açıya deklinasyon açısı denir. Deklinasyon açısı $-23,45^{\circ} \leq \delta \leq+23,45^{\circ}$ arasında değişmektedir. Cooper eşitliği olarak bilinen deklinasyon açısı aşağıdaki Eşitlik 8 ile hesaplanmaktadır [19]

$$
\delta=23.45 \sin [360(284+n) / 365]
$$

Burada, $n$ gün sayısı ifade etmekte olup, hesaplama yapılan günün yılbaşından itibaren kaçıncı gün olduğunu belirtmektedir.

HW Metodu ile 365 gün optimum eğim açı değerleri bulunmuştur. Bu çalışmada ay aritmetik ortalaması olarak hesaplanan açı, o ayın optimum eğim açısı olarak kabul edilmiştir. Aynı şekilde bu işlemler için de aylık, mevsimsel ve altı aylık için ortalamalar ayrı ayrı hesaplanmıştır.

Çalışmada, her iki metotta her ay, her mevsim ve her altı aylık optimum açı değerleri hesaplanmış ve karşılaştırılmıştır. Ayrıca PVGIS metodunda yapılan simülasyonda güneş paneli eğim açısının güneş ışınımı verimine etkisi saptanmıştır. 


\section{SONUÇLAR VE TARTIȘMALAR}

Şekil 3'de görüldüğü üzere; güneş 1şınları güneş panellerinin üzerine dik açıyla düştüğü zaman elektrik üretimi artış göstermektedir. Güneşi takip ederek güneş ışınlarının sürekli olarak dik alınmasını sağlayan sistemler geliştirilmektedir [20].

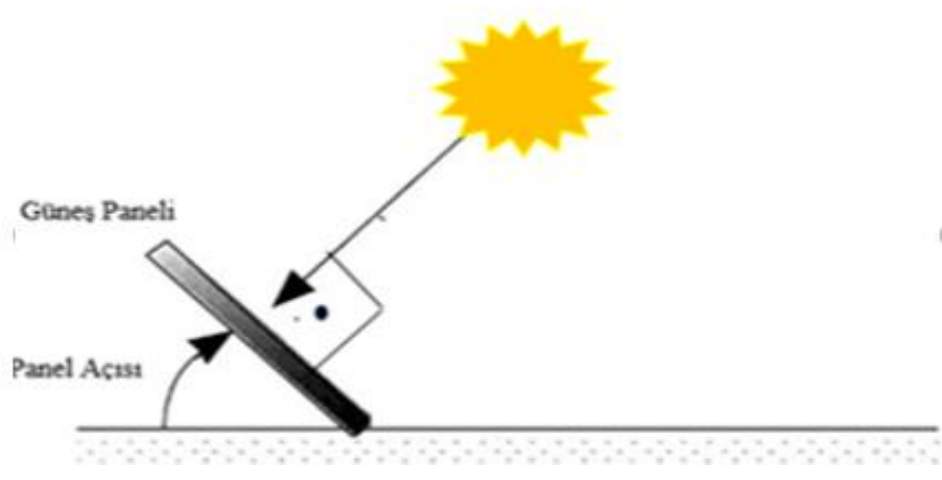

Şekil 3. Güneş ışınlarının panele dik gelmesi durumu

Tablo 1'de her ay için; PVGIS metodu ile hesaplanan maksimum güneş ışınımı, aylık panel optimum eğim açısı, HW metodu ile hesaplanan aylık panel optimum eğim açısı ve her iki metot arasındaki eğim açısı farkları görülmektedir.

Tablo 1 incelendiğinde, PVGIS metodunda güneş panelinin her ay sabit bir eğim açısı ile konumlandırılması durumunda güneş paneli eğim açısının $3^{\circ}$ ila $63,1^{\circ}$ arasında değişen değerler aldığı görülmektedir. Temmuz ayında $8,6^{\circ}$ optimum eğim açısında en büyük $242,4 \mathrm{kWh} / \mathrm{m}^{2}$ maksimum güneş ışınımı elde edilmiştir. Ocak ayında ise $56,2^{\circ}$ optimum eğim açısında en düşük $60,1 \mathrm{kWh} / \mathrm{m}^{2}$ maksimum güneş 1şınımı tespit edilmiştir. Güneşışınımının aylık optimum eğim açısı ile güneş paneline ulaşması durumunda maksimum $1852,3 \mathrm{kWh} / \mathrm{m}^{2} 1$ şınım elde edilmektedir.

Tablo 1'deki HW metodunda ise güneş panelinin her ay sabit bir eğim açısı ile konumlandırılması durumunda güneş paneli eğim açısının $15,6^{\circ}$ ila $61,8^{\circ}$ arasında değişen değerler aldığı görülmektedir.

Tablo 1. Aylık optimum eğim açısı ve maksimum güneş ışınımı değerleri [14, 19].

\begin{tabular}{|c|c|c|c|c|c|}
\hline \multirow{2}{*}{ Aylar } & \multirow{2}{*}{$\begin{array}{c}\text { HW Metodu } \\
\begin{array}{c}\text { Optimum } \\
\left.\text { eğim açısı ( }{ }^{\circ}\right)\end{array}\end{array}$} & \multicolumn{3}{|c|}{ PVGIS Metodu } & \multirow{2}{*}{$\begin{array}{c}\text { HW-PVGIS } \\
\text { optimum eğim açı farkı }\left({ }^{\circ}\right)\end{array}$} \\
\hline & & $\begin{array}{c}\text { Panel eğim } \\
\text { açısı aralığı }\left({ }^{\circ}\right)\end{array}$ & $\begin{array}{c}\text { Optimum } \\
\text { eğim açısı }\left({ }^{\circ}\right)\end{array}$ & $\begin{array}{l}\text { Maksimum güneş } \\
\text { Işınımı }\left(\mathbf{k W h} / \mathbf{m}^{2}\right) \\
\end{array}$ & \\
\hline Ocak & 59,5 & $53,3-59,1$ & 56,2 & 60,1 & 3,3 \\
\hline Şubat & 52,0 & $44,6-48,6$ & 46,6 & 70,4 & 5,4 \\
\hline Mart & 41,1 & $35-37,4$ & 36,2 & 116,9 & 4,9 \\
\hline Nisan & 29,2 & $22,8-26,3$ & 24,6 & 161 & 4,7 \\
\hline Mayıs & 19,9 & $9,9-13$ & 11,5 & 186,7 & 8,4 \\
\hline Haziran & 15,6 & $3-6,9$ & 5,0 & 214,7 & 10,6 \\
\hline Temmuz & 17,6 & $6,5-10,7$ & 8,6 & 242,4 & 9,0 \\
\hline Ağustos & 25,4 & $19,2-24,1$ & 21,7 & 235,3 & 3,7 \\
\hline Eylül & 36,7 & $35,1-37$ & 36,1 & 196,7 & 0,6 \\
\hline Ekim & 48,5 & $47,6-51$ & 49,3 & 155,9 & $-0,8$ \\
\hline Kasım & 57,7 & $58,8-61,6$ & 60,2 & 131,2 & $-2,5$ \\
\hline Aralık & 61,8 & $59,4-63,1$ & 61,3 & 81 & 0,5 \\
\hline Toplam & & & & 1852,3 & \\
\hline
\end{tabular}




\begin{tabular}{|c|c|c|}
\hline & $\begin{array}{l}\text { BŞEÜ Fen Bilimleri Dergisi } \\
8(1), 241-250,2021\end{array}$ & $\begin{array}{r}\text { BSEU Journal of Science } \\
\text { https://doi.org/10.35193/bseufbd.878795 }\end{array}$ \\
\hline 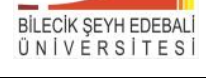 & & 2458-7575 (https://dergipark.org.tr/tr/pub/bseufbd) \\
\hline
\end{tabular}

Tablo 1 ve Şekil 4 incelendiğinde ise her iki metot arasındaki farkın 10,6 $6^{\circ}$ ye kadar çıktığı görülmüştür.

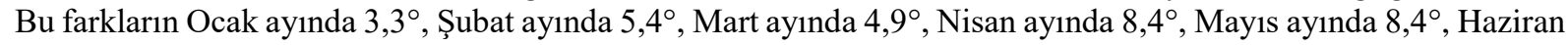
ayında $10,6^{\circ}$, Temmuz ayında $9^{\circ}$, Ağustos ayında 3,7 , Eylül ayında $0,6^{\circ}$, Ekim ayında $-0,8^{\circ}$, Kasım ayında $-2,5^{\circ}$ ve Aralık ayında $0,5^{\circ}$ olduğu tespit edilmiştir. Söz konusu Şekil 4 'deki her iki metot arasındaki farkın yaz aylarında büyüdüğü, Eylül, Ekim, Kasım ve Aralık aylarında ise tamamen yakınsadığı ve eğrinin bu aylarda birbiriyle örtüştüğü görülmektedir.

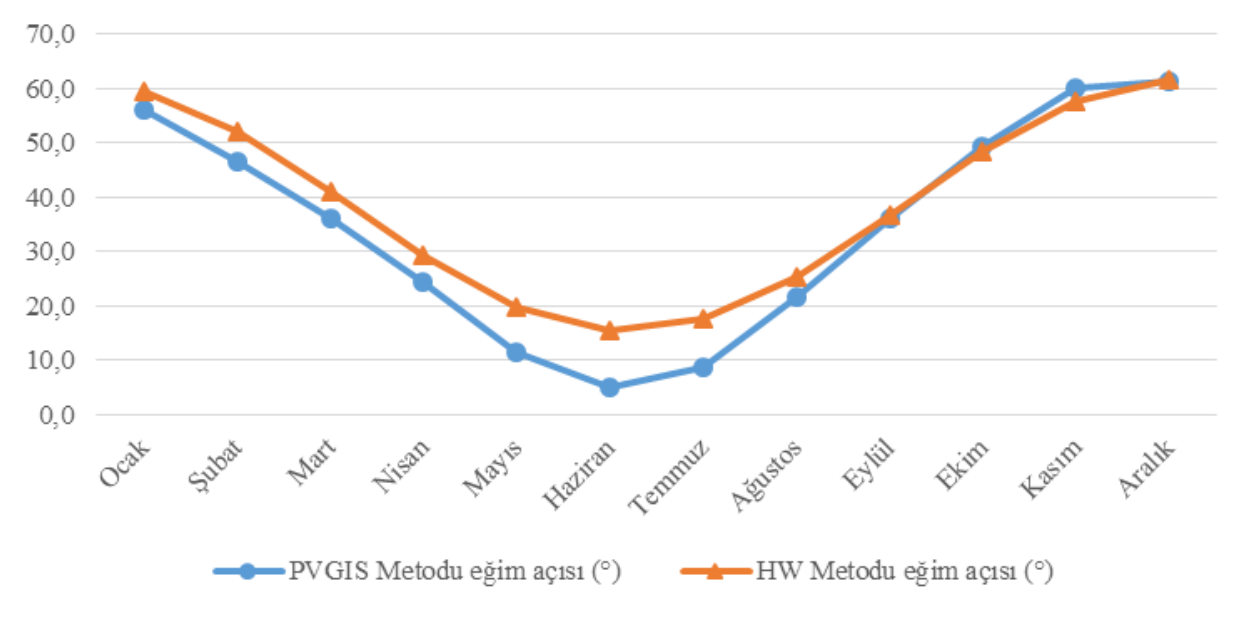

Şekil 4. PVGIS ve HW metodunda hesaplanan optimum eğim açısı dağılımı

Tablo 2'de her bir mevsim için; PVGIS metodu kullanılarak maksimum güneş 1şınımı değeri, panelin optimum eğim açısı, HW metodu ile elde edilen mevsimsel panel optimum eğim açısı ve her iki metot arasındaki eğim açısı farkları görülmektedir.

Tablo 2 incelendiğinde, PVGIS metodunda güneş panelinin mevsimsel sabit bir eğim açısı ile konumlandırılması durumunda güneş paneli eğim açısının $11,5^{\circ}$ ila 55,9 $9^{\circ}$ arasında değişen değerler aldı̆̆ görülmektedir. Tablo 2'de yaz mevsiminde $11,8^{\circ}$ optimum eğim açısında en yüksek $688,6 \mathrm{kWh} / \mathrm{m}^{2}$ maksimum güneş 1şınımı elde edilmiştir. Kış mevsiminde ise 55,4 optimum eğim açısında en düşük $210,6 \mathrm{kWh} / \mathrm{m}^{2}$ maksimum güneş ışınımı tespit edilmiştir. Güneş ışınlarının mevsimsel optimum eğim açısı ile güneş paneline ulaşmaları durumunda maksimum $1837 \mathrm{kWh} / \mathrm{m}^{2}$ güneş 1şınımı elde edilecektir.

Tablo 2'deki HW metodunda ise güneş panelinin her mevsim sabit bir eğim açısı ile konumlandırılması durumunda güneş paneli eğim açısının $19,5^{\circ}$ ila 57,8 arasında değişen değerler aldığı görülmektedir.

Tablo 2'de; her iki metot arasındaki farkın bahar ve yaz mevsiminde 7,8 'ye kadar çıktı̆̆ , Sonbahar ve kış mevsiminde ise farkın $1,1^{\circ}$ 'ye kadar düştüğü görülmüştür. İki metot arasındaki aylık kıyaslamada oluşan farklar sıfıra yaklaşırken mevsimsel farklarda ancak 1,1 ${ }^{\circ}$ ye kadar yaklaşmıştır.

Tablo 2. Mevsimlik optimum eğim açısı ve maksimum güneş ışınımı değerleri [14].

\begin{tabular}{lc|ccc|c}
\hline Aylar & $\begin{array}{c}\text { HW Metodu } \\
\text { Optimum eğim } \\
\left.\text { açısı ( }{ }^{\circ}\right)\end{array}$ & $\begin{array}{c}\text { Panel eğim } \\
\text { açısı aralığı }\left({ }^{\circ}\right)\end{array}$ & $\begin{array}{c}\text { Optimum } \\
\left.\text { eğim açısı ( }{ }^{\circ}\right)\end{array}$ & $\begin{array}{c}\text { Maksimum } \\
\text { güneş ışımımı } \\
\left(\mathbf{k W h} / \mathbf{m}^{2}\right)\end{array}$ & $\begin{array}{c}\text { HW-PVGIS } \\
\text { optimum eğim açı } \\
\left.\text { farkı ( }{ }^{\circ}\right)\end{array}$ \\
\hline Kış & 57,8 & $54,8-55,9$ & 55,4 & 210,6 & 2,4 \\
İlkbahar & 30,1 & $20,8-23,8$ & 22,3 & 460 & 7,8 \\
Yaz & 19,5 & $11,5-12,1$ & 11,8 & 688,6 & 7,7 \\
Sonbahar & 47,6 & 46,5 & 46,5 & 477,8 & 1,1 \\
\hline \multicolumn{7}{l|}{ Toplam } \\
\hline
\end{tabular}


Tablo 3'de her altı aylık dönemler için; PVGIS metodu kullanılarak maksimum güneş ışınımı değerindeki panelin optimum eğim açısı, HW metodu ile elde edilen altı aylık panel optimum eğim açısı ve her iki metot arasındaki eğim açısı farkları görülmektedir.

Tablo 3 incelendiğinde, PVGIS metodu ile altı aylık ilkbahar-yaz döneminde $16,1^{\circ}$ optimum eğim açısında en yüksek $1145,3 \mathrm{kWh} / \mathrm{m}^{2}$ maksimum güneş 1şınımı elde edilmiştir. Sonbahar-kış döneminde ise $49,3^{\circ}$ optimum eğim açıısında en düşük $687,1 \mathrm{kWh} / \mathrm{m}^{2}$ maksimum güneş 1şınımı tespit edilmiştir. Güneş 1şınlarının altı aylık optimum eğim açısı ile güneş paneline ulaşmaları durumunda maksimum $1832,4 \mathrm{kWh} / \mathrm{m}^{2}$ güneş ışınımı elde edilecektir. HW metodunda ise güneş panelinin altı aylık dönemlerde sabit bir eğim açısı ile konumlandırılması durumunda güneş paneli eğim açısının ilkbahar- yaz dönemindeki altı ayda $24,8^{\circ}$, sonbahar ve kış dönemindeki altı ayda ise $52,7^{\circ}$ olduğu tespit edilmiştir.

Tablo 3'de; her iki metot arasındaki farkın ilkbahar- yaz dönemindeki altı ayda 8,7'ye kadar çıktığı, sonbahar ve kış dönemi altı ayda ise farkın 3,4'ye kadar düştüğü görülmüştür. Bu farkların aylık farklara göre birbirine daha çok yaklaştı̆̆ görülmüştür.

İki metot arasındaki aylık kıyaslamada oluşan farklar sıfıra yaklaştığı, mevsimsel farkların 1,1 ${ }^{\circ}$ ye kadar ve altı aylık dönemlerdeki farkların ise $3,4^{\circ}$ 'ye kadar yaklaştı̆̆ı görülmüşsür.

Tablo 3. Altı aylık optimum eğim açısı ve maksimum güneş ışınım değerleri [14]

\begin{tabular}{|c|c|c|c|c|c|}
\hline & HW Metodu & \multicolumn{3}{|c|}{ PVGIS Metodu } & \multirow[b]{2}{*}{$\begin{array}{c}\text { HW-PVGIS } \\
\text { optimum eğim açı farkı }\left({ }^{\circ}\right)\end{array}$} \\
\hline Aylar & $\begin{array}{l}\text { Optimum eğim } \\
\text { açısı ( }\left(^{\circ}\right)\end{array}$ & $\begin{array}{c}\text { Panel eğim } \\
\text { açısı aralığı } \\
\left({ }^{\circ}\right)\end{array}$ & $\begin{array}{l}\text { Optimum eğim } \\
\operatorname{açısı~}\left({ }^{\circ}\right)\end{array}$ & $\begin{array}{l}\text { Maksimum günes } \\
\text { Işınımı }\left(\mathbf{k W h} / \mathbf{m}^{2}\right)\end{array}$ & \\
\hline Sonbahar-Kış & 52,7 & $47,8-50,8$ & 49,3 & 687,1 & 3,4 \\
\hline İlkbahar-Yaz & 24,8 & $15,5-16,7$ & 16,1 & 1145,3 & 8,7 \\
\hline Toplam & & \multicolumn{4}{|c|}{1832,4} \\
\hline
\end{tabular}

Diğer taraftan, PVGIS metodu ile güneş panelinin sabit bir eğim açısı ile konumlandırılması ile bir yılda panele düşen maksimum güneş 1şınımı değeri $1779,55 \mathrm{kWh} / \mathrm{m}^{2}$ ve panelin optimum eğim açı1sı ise $29,5^{\circ}$ olarak tespit edilmiştir.

Tablo 4'de PVGIS metodunda güneş paneline düşen güneş ışınımları aylık, mevsimlik, altı aylık ve yıllık olarak verilmiştir. Söz konusu Tabloda yıllık sabit optimum eğim açısına göre en yüksek verimin yüzde 4,11 ile aylık optimum panel açısından elde edilmiştir. Ayrıca, panelin sabit eğim açısı yerine altı ayda bir değişim olması halinde verimin \%2,99 arttığı, mevsimsel olarak değiştirilmesi halinde ise \%3,25 arttığı tespit edilmiştir. Panelin mevsimsel ve altı aylık optimum eğim açıları karşılaştırıldığında ise verim farkının yüzde 0,26 olduğu saptanmıştır. Bu 0,26'lık farkın düşük olması, güneş panellerinin yılda iki kez eğim açısı değişimi (altı aylık) yapılarak konumlandırmasının uygun olacağını göstermiştir. Bu sonuçların literatürle uyumlu olduğu görülmüştür $[3,10]$.

Tablo 4. Optimum açılara göre PVGIS metodundaki yıllık toplam maksimum güneş ışınım değerleri

\begin{tabular}{lcccc}
\hline & Aylık değişim & Mevsimlik değişim & $\begin{array}{c}\text { Altı aylık } \\
\text { değişim }\end{array}$ & Yıllık (sabit) \\
\hline Güneş 1şınımı & 1852,30 & 1837,00 & 1832,40 & 1779,25 \\
Yüz oranı (\%) & 4,11 & 3,25 & 2,99 & 0,00 \\
\hline
\end{tabular}

Bu kapsamda, güneş panellerinin aylık optimum eğim açısı ile konumlandırılmaları durumunda güneş ışınımından en yüksek verim elde edilecektir.

Çalışmada, Ocak, Ağustos, Eylül, Ekim, Kasım ve Aralık aylarında farkın bir derecenin altında oluşması HW metodu ile optimum eğim açısı tespitinde bu aylar için kullanılmasının büyük hatalara neden olmayacağı Tablo 1'de görülmektedir. Aynı şekilde mevsimsel ve altı aylık durumlar için Sonbahar ve Kış mevsimlerinde farkın küçük olması HW metodu ile optimum eğim açısı tespitinde belirtilen mevsimlerde de kullanılmasının uygun olacağı öngörülmektedir. 


\section{SONUÇLAR}

Yapılan hesaplamalar sonucunda; Kayseri'de kullanılan güneş panellerinin verimini artırması yönelik PVGIS ve Hottel \& Woertz metotları ile yapılan hesaplamalar sonucunda;

- PVGIS ve HW metotları karşılaştırıldığında Eylül, Ekim, Kasım ve Aralık aylarındaki panel eğim açılarının birbiriyle örtüştüğü,

- PVGIS ve HW metotları arasındaki eğim açısı farkının yaz aylarında $10,6^{\circ}$ 'ye kadar çıktığı, Nisan, Mart, Şubat ve Ocak aylarında ise eğim açı farkının $3,3^{\circ}$ 'ye kadar düştüğü,

- PVGIS metodunda güneş panellerinin her ay sabit bir optimum eğim açısı ile konumlandırılması durumunda panellere $1852,3 \mathrm{kWh} / \mathrm{m}^{2}$ maksimum güneş ışınımının ulaşacağı,

- Güneşı ışıllarının mevsimsel optimum eğim açısı ile konumlandırılması durumunda panellere $1837 \mathrm{kWh} / \mathrm{m}^{2}$ maksimum güneş ışınımının ulaşacağı,

- Güneş ışınlarının altı aylık optimum eğim açısı ile konumlandırılması durumunda panellere $1832,4 \mathrm{kWh} / \mathrm{m}^{2}$ maksimum güneş ışınımının ulaşacağ 1 ,

- Yıllık optimum eğim açısına göre en yüksek verimin yüzde 4,11 ile aylık (yılda on iki kez değişimle) optimum panel açısından elde edildiği,

- Mevsimsel ve altı aylık optimum eğim açıları karşılaştırıldığında güneş panellerinin pratik olarak altı aylık (yılda iki kez değişimle) optimum panel açısına göre konumlandırma yapılmasının uygun olacağı,

- Kayseri’nin güneş enerjisi potansiyeli bakımından avantajlı iller arasında yer aldığı,

tespit edilmiş̧ir.

PVGIS ve HG metotları güneş panellerinin optimum eğim açısının belirlenmesinde Kayseri'deki yatırımcılara ve araştırmacılara kolaylık sağlayacaktır.

\section{KAYNAKLAR}

[1] Roberts, S. \& Guariento, N. (2009). Building Integrated Photovoltaics A Handbook. Berlin, Germany. Birkhauser Press.

[2] Kaldellis, J. \& Zafirakis, D. (2012). Experimental investigation of the optimum photovoltaic panels tilt angle during the summer period. Energy, 38(1), 305-14.

[3] Lubitz, W. D. (2011). Effect of manual tilt adjustments on incident irradiance on fixed and tracking solar panels. Applied Energy, 88(5), 1710-1719.

[4] Ülgen, K. (2006). Optimum Tilt Angle For Solar Collectors. Energy Sources, Part A: Recovery, Utilization, and Environmental Effects, 28(13), 1171-1180.

[5] Bulut, H., Büyükalaca, O. \& Yılmaz, T. (1999). Bazı İller İçin Güneş Işınım Şiddeti, Güneşlenme Süresi ve Berraklık İndeksinin Yeni Ölçümler Işı̧ı̆ında Analizi. Güneş Günü Sempozyumu’99. 25 Haziran, Kayseri.

[6] Khatib T., Mohamed A., Mahmoud M. \& Sopian K. (2015). Optimization of the Tilt Angle of Solar Panels for Malaysia. Energy Sources, Part A: Recovery, Utilization, and Environmental Effects, 37(6), 606-61.

[7] Le Roux W. G. (2016).Optimum Tilt and Azimuth Angles for Fixed Solar Collectors in South Africa Using Measured Data. Renewable Energy, 96(A), 603-612.

[8] Yıldırım, E. \& Aktacir, M. (2019). Binaya Entegre Fotovoltaik Sistemlerde Azimut ve Eğim Açısı Etkilerinin İncelenmesi. Gazi Üniversitesi Mühendislik Mimarllk Fakültesi Dergisi, 34(2), 609-620.

[9] Çağlar, A. (2018). Farklı Derece-Gün Bölgelerindeki Şehirler İçin Optimum Eğim Açısının Belirlenmesi, Süleyman Demirel Üniversitesi Fen Bilimleri Enstitüsü Dergisi, 22(2), 849-854.

[10] Koçer, A., Şevik, S. \& Güngör, A. (2016). Ankara ve İlçeleri İçin Güneş Kolektörü Optimum Eğim Açısının Belirlenmesi. Uludağ University Journal of The Faculty of Engineering, 21(1), 63-78.

[11] Aydın, M. (2020). Türkiye Koşullarında Güneş Panelleri İçin Optimum Sabit ve Ayarlanabilir Eğim Açılarının Belirlenmesi Üzerine Bir Araştırma. Yüksek Lisans Tezi, Bursa Uludağ Üniversitesi Fen Bilimleri Enstitüsü, Bursa.

[12] Enerji ve Tabi Kaynaklar Bakanlığı (ETKB). 2020. Güneş Enerjisi Potansiyel Atlası (GEPA). http://www.yegm.gov.tr/MyCalculator/. (Erişim tarihi: 15.12.2020).

[13] Oğuz, M. \& Akkurt, Ş. (2017). Kayseri İlinin Yenilenebilir Enerji Potansiyeli. Niğde Ömer Halisdemir Üniversitesi Mühendislik Bilimleri Dergisi, 6(2), 362-374.

[14] European Commission (EU). (2020). Photovoltaic Geographical Information System (PVGIS). https://ec.europa.eu/jrc/en/PVGIS/docs/methods, (Erişim tarihi: 15.12.2020). 
[15] Gracia A. M. \& Huld T. (2013). Performance comparison of different models for the estimation of global irradiance on inclined surfaces. European Commission Joint Research Centre Institute for Energy and Transport. https://op.europa.eu/en/publication-detail/-/publication/4ef8c4e1-4397-4e27-8487448786327f27. (Erişim tarihi: 15.07.2020).

[16] Muneer T. (1990). Solar radiation model for Europe. Building Services Engineering Research and Technology, 11(4), 153-163.

[17] Camelia, S. \& Dorin, S. (2014). Optimum Tilt Angle for Flat Plate Collectors All Over the World-A Declination Dependence Formula and Comparisons of Three Solar Radiation Models. Energy Conversion and Management, 81, 133- 143

[18] Soulayman, S. \& Hammoud, M. (2016). Optimum Tilt Angle of Solar Collectors for Building Applications in Mid-Latitude Zone. Energy Conversion and Management, 124, 20-28

[19] Cooper, P. I. (1969). The Absorption of Solar Radiation in Solar Still, Solar Energy, 12(3), $333-46$.

[20] Vasarevicius, D. \& Martavicius, R. (2011). Solar İrradiance Model for Solar Electric Panels and Solar Thermal Collectors in Lithuania. Electronics and Electrical Engineering, 108(2), 3-6. 